\title{
Prediction of postpartum depression based on women's quality of life
}

\author{
BITA PARSA ${ }^{1, A, C-F}$, PARISA PARSA ${ }^{2, ~ A-G}$, BANAFSHEH BOOJARZADEH ${ }^{1, A-c, ~ E, ~ F, ~}$ \\ ORCID ID: 0000-0002-2834-2470
}

YOUNES MOHAMMADI $\left.\right|^{3, A, C, E}$

${ }^{1}$ Department of Management, Naser Khosrow Higher Education Institute, Saveh, Iran

${ }^{2}$ Chronic Diseases (Home Care) Research Centre, Hamadan University of Medical Sciences, Hamadan, Iran

${ }^{3}$ Modelling of Noncommunicable Diseases Research Centre, Department of Epidemiology, School of Public Health, Hamadan University of Medical Sciences, Hamadan, Iran

A - Study Design, B - Data Collection, C - Statistical Analysis, D - Data Interpretation, E - Manuscript Preparation, F - Literature Search, G - Funds Collection

Summary Background. Postpartum depression is the most common problem after childbirth.

Objectives. To determine the level postpartum depression, quality of life and predict postpartum depression based on the quality of life of women.

Material and methods. This was a descriptive cross-sectional study. The research population consisted of women who were reporting to health care centres in Hamadan, Iran, 2 to 4 weeks after delivery. A total of 300 eligible women were selected using the cluster sampling method. The data gathering tool was a questionnaire that consisted of three sections: demographic characteristics, Short Form Health Survey (SF-36) and Edinburgh depression questionnaire. SF-36 was used to measure quality of life, which includes eights dimension. Data was analysed using SPSS version 21. Descriptive statistics, Pearson' correlation and linear multiple regression analysis were used.

Results. The mean age was $28.6 \pm 5.2$ years. The average quality of life scores in individuals were within a moderate level, the highest score was related to physical function, and the lowest score was related to role impairment due to physical health. Postpartum depression was determined in $25 \%$ of women, of which $7 \%$ had severe depression. Physical functioning $(p=0.32)$, role impairment due to emotional health $(p=002)$, energy/fatigue $(p=0.010)$, emotional well-being $(p=002)$ and social function $(p=0.002)$ were significant predictors of postpartum depression.

Conclusions. Considering the high rate of postpartum depression, improving quality of life aspects, early diagnosis of postpartum depression and appropriate care for women after childbirth, especially those of a low socio-economic status, are suggested.

Key words: quality of life, depression, postpartum period, puerperal disorders, Iran.

Parsa B, Parsa P, Boojarzadeh B, Mohammadi Y. Prediction of postpartum depression based on women's quality of life. Fam Med Prim Care Rev 2019; 21(4): 343-348, doi: https://doi.org/10.5114/fmpcr.2019.90165.

\section{Background}

Women often experience some level of sadness and depression after childbirth. This is associated with the collapse of hormonal levels after delivery, the responsibility of taking care of the baby, breastfeeding and adopting new maternal roles [1]. Pregnancy and childbirth are associated with many physical and emotional changes in life that can affect women's quality of life [2]. Quality of life is a feeling of goodness, and according to the World Health Organization, quality of life is related to physical, psychological, social, environmental and spiritual aspects [3]. Quality of life as a criterion is important for evaluation of success in healthcare and treatment [4]. Various factors affect the quality of life of women after delivery, including type of delivery, as well as clinical, psychological, social and obstetric factors [5-7]. Women during childbirth experience a lot of physiological and psychological changes. Thus, they need more attention in this period $[8,9]$. The most common disorder in the postpartum period is sadness (blues) and postpartum depression [10]. The severity of the blues is usually mild, but sometimes it remains for more than ten days [11]. Symptoms of this disorder are fear, irritability, drowsiness, disturbance in concentration, headache, isolation and abnormal imagination [12, 13].
The exact cause of postpartum depression is not known, but it is often attributed to severe hormonal changes immediately after childbirth [14]. The emotional separation of the foetus from the mother and the mother's adaptation to changes in pregnancy may be other reasons for postpartum depression [15]. With the occurrence of childbirth, all of the above is lost, and the mother feels empty. This vulnerability, along with a feeling of insecurity in the role of a new mother, can reduce the confidence of the mother [16]. Postpartum depression reduces the emotional dependence of the mother and infant. It effects a mother's self-esteem, the adaptation of the mother's role, care of the baby and breastfeeding $[17,18]$.

Depression also causes behavioural and developmental abnormalities in the child and decreases parental attachment [19]. Depression felt by the mother and father during the postpartum period effects the interactions between the infant and parents [20]. It has been reported that low parental attachment to a child, even during childhood and adolescence periods, is associated with decreased self-efficacy and the self-esteem of the child [21, 22].

Attention to the physical and mental health of mothers has an important impact on women's health after childbirth [23]. One of the goals of the World Health Organization is to improve maternal health and reduce mortality and morbidity. 
According to the organisation's statistics, the highest mortality and morbidity of mothers occur after delivery. Therefore, postpartum care is very essential to evaluate maternal health and the health of the child, delivery complications, the mother-child relationship, breastfeeding, the husband's and wife's support and family planning [24]. Studies have shown that breastfeeding training based on the BASNEF model decreased the intensity of postpartum blues $[18,25]$. Interventions for reducing any sleep disorders of mothers after childbirth [26], increasing physical activity and exercise [27], aromatherapy after delivery $[28,29]$ and performing yoga $[30]$ had a positive effect on the reduction of postpartum depression. Self-empowerment affirmation relaxation (Self-EAR) [31] and structured education for the decrease of postpartum blues and depression were also useful [32]. Furthermore, studies have shown that women's health performance after childbirth was affected by their clinical and obstetrical status, socio-demographic status and the perceived barriers when looking for expert help [33, 34]. Screening for postpartum depression and early physical and mental disorders during the postpartum period by health professionals and midwives can minimise the adverse effects of postpartum depression, and this is a cost-effective method to increase the mother-child health status and family relationships [35, 36]. On the other hand, improving the quality of life of mothers during postpartum is a guarantor of the health status of the mother, infant and family.

\section{Objectives}

The objectives of this study were to determine the levels of postpartum depression and quality of life in women after childbirth and to predict postpartum depression based on the quality of life among women reporting to health centres in Hamadan, Iran.

\section{Material and methods}

\section{Study design}

This study was a cross-sectional study.

\section{Participants and sample size}

The research population consisted of women who were reporting to health centres for postpartum care in Hamadan, Iran, from October 2016 to May 2017. The inclusion criteria included: Iranian citizenship, having a wanted pregnancy, between 18-40 year of age, childbirth in 2-4 week ago, singleton delivery, normal neonatal weight, having a healthy new-born child, living with their spouse. Excluding criteria included: a history of mental problems, having stress or family problems, hospitalisation of the mother or the baby after childbirth. Considering the previous study, if the type 1 error is $5 \%$, with a standard deviation of 4 and a precision of 0.74 , the estimated sample size for this study is 256 people [37]. With the probability of some questionnaires not being fully answered, 300 people were selected.

$$
n=\frac{z^{2} p(1-p)}{d^{2}}
$$

\section{Sampling method}

The sampling method utilised the two-stage cluster sampling method. First, a health care centre was randomly selected in each area of Hamadan: North, South, Centre, West and East. The sample was then randomly selected in the five eligible health care centres. Using a random number table, eligible women were randomly selected from the list of households in each centre. Women were telephoned and asked to come to the health care centres for postpartum care. The study was explicitly explained to the mothers, and those who were willing to participate in the study filled out the informed consent form. Approximately 80 women in each health centre were enrolled in the study. The data gathering tool was a questionnaire consisting of three parts: background information, SF-36 questionnaire and Edinburgh postpartum depression scale.

\section{Data collection tool}

The data was collected by interviewing the mothers and completing the questionnaire by the researcher. Background information included age, height, weight, employment status, women's education and husbands' education level. The type of delivery, the number of children, the sex of the baby and the health status of the mother and the baby were also asked.

Quality of life of mothers was assessed using the 36-item Short Form Health Survey. Each subscale consists of 2 to 10 items. The 8 subscales of this questionnaire are: Physical Functioning (PF), Role Impairment due to Physical Health (RP), Role Impairment due to Emotional Health (RE), Energy/Fatigue (EF), Emotional Well-being (EW), Social Function (SF), Pain (P) and General Health (GH). In this questionnaire, lower scores represent the lower quality of life and vice versa. Each question has a score between 0 (lowest score) and 100 (highest score). By the aggregation of scores, the score of the individual concerning each subscale was obtained. The validity and reliability of the SF-36 questionnaire in Iran were determined by Bahrami and Bahrami. In 2012, they examined the content validity method for its validity and Cornbrash's alpha coefficient of 0.81 for the reliability [4]. In this study, the reliability of SF-36 was confirmed by Cornbrash's alpha coefficient equal to 0.78 .

The Edinburgh Postpartum Depression Scale (EPDS) is a standardised tool for screening postpartum depression in women. This tool determines women's emotions over the past week. The questionnaire consists of 10 questions, and the response ranges between " 0 " to " 3 ". The sum of the scores determines the overall test score. The borderline of depression in postpartum mothers in the general population is 10 , while a severe onset of depression is 14 [38]. The Edinburgh questionnaire in Iran was evaluated by Montazeri et al. and his colleagues, and its validity and reliability were measured. Cronbach's alpha coefficient for reliability was reported to be 0.8 [39]. In this study, the reliability of EPDS was confirmed by Cornbrash's alpha coefficient equal to 0.85 .

\section{Ethical consideration}

The protocol of this study was approved by the Ethics Committee of the Hamadan University of Medical Sciences (Ref No: IR.UMSHA.REC.1395.423). The study obtained the permission of the Research Deputy of the Hamadan University of Medical Sciences and the heads of the selected health care centres of Hamadan city, Iran.

\section{Statistical analysis}

SPSS software version 21 was used for data analysis. Using the Kolmogorov-Smirnov test, normal distribution of SF-36 dimensions and EPDS were confirmed $(p<0.05)$. Independent $t$-test and one-way analysis of variance were used to compare the mean of groups. Pearson's correlation test was used to examine the relationship between the dimensions of SF-36 and postpartum depression. Linear multiple regression analysis was used to detect the prediction effect of quality of life dimensions on postpartum depression.

\section{Results}

Based on the results in Table 1, the mean (SD) age of women was 26.8 (6.2) years, and most of them were between 21 to 30 
years. Half of the women had graduated. Most of the women were housewives. A little more than half of the participants had a normal delivery. The gender of the infants was $51 \%$ male and $49 \%$ female. About $90 \%$ of mothers had planned or wanted pregnancies. The mean age of the spouses was 34.82 years, with a standard deviation of 6.6 years. Most of them had postgraduate degrees, and $96 \%$ were employed. Only $10 \%$ of the women reported to be in a good economic situation.

The findings show that the highest mean scores of quality of life dimensions were related to physical function (80.576 $\pm 24.04891)$ and social function (65.226 \pm 25.09$)$, respectively. While the lowest mean scores were related to role impairment due to physical health $(23.928 \pm 10.91)$ and emotional health (38.148 \pm 19.79$)$. The results show that about $25 \%$ of women reported a degree of postpartum depression, of which $16 \%$ had mild depression $(10<$ score $<14)$ and $7 \%$ had severe depression (score $>14$ ) after childbirth.

According to Table 2, there is a significant and inverse correlation between postpartum depression with physical function ( $p<0.001)$, emotional well-being $(p<0.001)$, social function $(p<0.001)$ and general health $(p<0.001)$. There is also a significant and positive correlation between postpartum depression and role impairment due to physical health $(p<0.001)$ and role impairment due to emotional health $(p<0.001)$. There was no significant correlation between energy/fatigue and pain with PPD $(p>0.05)$.

In the linear regression analysis using the stepwise method (Table 3), demographic variables such as the age of the mother, education, occupation, the method of delivery and subscales of quality of life dimensions were included. Of these independent variables, only the dimensions of quality of life were predictors of postpartum depression. This model was an acceptable model for predicting the effect of independent variables on postpartum depression, with a predictive value of about $29 \%$. In this model, emotional well-being (Beta $=-3.206, p=0.002$ ), social function (Beta $=-3.128, p=0.002$ ) and role impairment due to emotional health (Beta $=3.110, p=0.002$ ), energy/fatigue
(Beta $=2.600, p=0.010$ ) and physical function (Beta $=-2.160$, $p=0.032$ ) were predicators of postpartum depression.

\begin{tabular}{|c|c|c|c|}
\hline Characteristics & $n$ & $\%$ & Mean (SD) \\
\hline $\begin{array}{l}\text { Age } \\
\qquad \begin{array}{l}<20 \\
21-30 \\
31-40\end{array}\end{array}$ & $\begin{array}{l}43 \\
178 \\
79\end{array}$ & $\begin{array}{l}14.3 \\
59.3 \\
26.4\end{array}$ & $26.866(5.21)$ \\
\hline $\begin{array}{l}\text { Education levels } \\
\text { illiterate } \\
\text { primary } \\
\text { secondary } \\
\text { tertiary } \\
\end{array}$ & $\begin{array}{l}13 \\
24 \\
212 \\
51\end{array}$ & $\begin{array}{l}4.3 \\
8.0 \\
70.7 \\
17.0 \\
\end{array}$ & \\
\hline $\begin{array}{l}\text { Occupation } \\
\text { housewife } \\
\text { employed }\end{array}$ & $\begin{array}{l}18 \\
282\end{array}$ & $\begin{array}{l}6.0 \\
94.0\end{array}$ & \\
\hline $\begin{array}{l}\text { Number of children } \\
1 \\
2 \\
3 \\
4 \\
\end{array}$ & $\begin{array}{l}135 \\
103 \\
46 \\
16\end{array}$ & $\begin{array}{l}45.0 \\
34.3 \\
15.3 \\
5.4\end{array}$ & $1.871(0.82)$ \\
\hline $\begin{array}{l}\text { Delivery method } \\
\text { normal vaginal delivery } \\
\text { caesarean }\end{array}$ & $\begin{array}{l}163 \\
137\end{array}$ & $\begin{array}{r}54.3 \\
47.5 \\
\end{array}$ & \\
\hline $\begin{array}{l}\text { Planned pregnancy } \\
\text { yes } \\
\text { no }\end{array}$ & $\begin{array}{l}267 \\
33 \\
\end{array}$ & $\begin{array}{l}89.0 \\
11.0 \\
\end{array}$ & \\
\hline $\begin{array}{l}\text { Economic status } \\
\text { poor } \\
\text { moderate } \\
\text { good }\end{array}$ & $\begin{array}{l}84 \\
185 \\
31\end{array}$ & $\begin{array}{l}28.0 \\
61.6 \\
10.4\end{array}$ & \\
\hline $\begin{array}{l}\text { Neonate sex } \\
\text { male } \\
\text { female }\end{array}$ & $\begin{array}{l}153 \\
147\end{array}$ & $\begin{array}{l}51.0 \\
49.0\end{array}$ & \\
\hline
\end{tabular}

\begin{tabular}{|c|c|c|c|c|c|c|c|c|c|}
\hline & PPD & PE & RP & RE & EF & EW & SF & P & GH \\
\hline PPD & 1 & & & & & & & & \\
\hline $\mathrm{PE}$ & $-0.233^{*}$ & 1 & & & & & & & \\
\hline RP & $0.194 *$ & $-0.452^{*}$ & 1 & & & & & & \\
\hline RE & $0.404 *$ & $-0.342^{*}$ & $0.532^{*}$ & 1 & & & & & \\
\hline EF & -0.062 & -0.072 & 0.081 & 0.026 & 1 & & & & \\
\hline EW & $-0.343^{*}$ & -0.032 & 0.103 & -0.032 & $0.666^{*}$ & 1 & & & \\
\hline SF & -0.457 & $0.337^{*}$ & $-0.455^{*}$ & $-0.520 *$ & 0.070 & $0.195^{*}$ & 1 & & \\
\hline$P$ & 0.090 & 0.026 & 0.023 & 0.049 & 0.024 & -0.074 & 0.014 & 1 & \\
\hline GH & $-0.394^{*}$ & $0.313^{*}$ & $-0.270^{*}$ & $-0.332^{*}$ & $0.215^{*}$ & $0.220^{*}$ & $0.296 *$ & 0.025 & 1 \\
\hline
\end{tabular}

$* p<0.05$.

\begin{tabular}{|l|l|l|l|l|l|}
\hline \multicolumn{6}{|c|}{ Table 3. Linear regression analysis of prediction of postpartum depression based on quality of life } \\
\hline Variables & B & SE & Beta & $t$ & $p$ \\
\hline (Constant) & 14.855 & 2.056 & & 7.224 & 0.000 \\
\hline PF & -0.037 & 0.017 & -0.155 & -2.160 & 0.032 \\
\hline RP & -0.011 & 0.011 & -0.073 & -0.944 & 0.346 \\
\hline RE & 0.029 & 0.009 & 0.234 & 3.110 & 0.002 \\
\hline EF & 0.053 & 0.020 & 0.230 & 2.600 & 0.010 \\
\hline EW & -0.082 & 0.026 & -0.293 & -3.206 & 0.002 \\
\hline SF & -0.045 & 0.014 & -0.222 & -3.128 & 0.002 \\
\hline P & 0.014 & 0.018 & 0.048 & 0.773 & 0.440 \\
\hline GH & -0.025 & 0.018 & -0.098 & -1.402 & 0.162 \\
\hline
\end{tabular}

$R=0.537, R$ square $=0.289$, Adjusted $R$ square $=0.259, F(8) 195=9.891, p<0.01 ;$ DV: postpartum depression . 


\section{Discussion}

The results showed that $25 \%$ of the women experienced postpartum depression. The prevalence of depression in different countries ranged from $10 \%$ to $30 \%[40,41]$. The prevalence of postpartum depression was reported as $33.7 \%$ in Zahedan, Iran [42], 40\% in the United States [43] and 45\% in Kuwait [44]. Differences in the rate of depression can be attributed to the difference in data collection tools, questionnaires, family support and lifestyle in different areas. Even one in four women could get postpartum depression (PPD) after delivery, and the results of research on 100 married adult women aged 21 to 40 years showed that only about half of them knew about PPD. The largest causes of PPD, in their view, were little support from family and friends (7\%), anxiety about the new-born child (6\%), history of depression (2\%), marital issues (3\%), financial problems (3\%), lack of relaxation (8\%) and thinking that it may be due to a combination of all factors (72\%) [2]. This shows the need for education and screening programmes to promote women's awareness about postpartum depression in developing countries.

In this study, there was no association between the occurrence of PPD with obstetrical complication and method of delivery. In contrast, the findings of a cohort study performed on primiparous women of a large Danish population showed that hyperemesis-gravidarum, hypertension, pre-eclampsia, and caesarean section were associated with increased risk of PPD [7]. Similarly, a study on women in rural Indian revealed that vaginal delivery (even with an episiotomy) was associated with higher postpartum quality of life (QoL) than caesarean delivery [45]. Differences between the results of the current study and other studies may be due to the number of samples, area of study, study design and tools of data collection.

The findings of this study indicated that most domains of quality of life were at moderate levels. The highest mean scores of quality of life dimensions were related to physical and social function, while emotional health was the lowest. Similarly, in the study of Bahrami and Bahrami, physical performance and emotional health were the highest and lowest scores, respectively [4]. In addition, postpartum depression has a negative effect on women's emotional and cognitive ability to bond with her child and family. Therefore, the child is at greater risk of developmental disorders [46]. Negative associations were found between mothers' postpartum depression and the physical health, cognitive development and language development of their children [47].

In the current research, the findings showed a significant relationship between postpartum depression and the subscales of quality of life. Similar results were reported in previous studies. A study in Turkey showed a negative relationship between depression and quality of life of mothers $(p<0.05)$. As mothers' depression scores decreased, their quality of life scores increased. Postpartum depression was associated with women's education level, and quality of life was associated with the parity of mothers [15]. Another study in Iran showed that there were significant differences in the quality of life dimensions between postpartum depressed and non-depressed women. From the $4^{\text {th }}$ to $16^{\text {th }}$ week of postpartum, depressed women scored lower on all quality of life dimensions compared to non-depressed women [48]. Da Costa et al. conducted a study to assess quality of life among women with postpartum depression. They examined the relationship between the severity of depression symptoms and the level of physical and mental impairment. The results showed that depressed women had lower scores of QoL, especially in physical health, compared to non-depressed women. After controlling the severity of depression, factors such as the occurrence of complications of pregnancy, caesarean delivery, poor sleep quality, life stress and low social support were associated with postpartum depression [49]. Similar results were reported by other studies in other countries [6, 7]. A study in Kuwait revealed a reverse relationship between PPD and women's quality of life (in terms of physical and psychological health). Negative relationship was found between PPD and the total score of quality of life $(B=-1.35)$, physical health $(B=-1.23)$ and mental health $(B=-1.46)[44]$. Zubaran and Foresti performed a study in Brazil to investigate the relationship between postpartum depression and quality of life. The results showed that socio-economic status and quality of life significantly affected the symptoms of depression. These findings suggest that a low socio-economic status and quality of life can have an effect on postpartum depression. The results also emphasise the importance of psychosocial risk factors in postpartum depression [50]. Feki et al. conducted a study to determine the effect of delivery experiences and quality of life on postpartum depression in women. The results showed that the prevalence of postpartum depression was $14.7 \%$ and $19.8 \%$ in the $1^{\text {st }}$ and $6^{\text {th }}$ week after delivery, respectively. Quality of life scores were significantly lower in depressed women compared to non-depressed women [51]. Due to the changes in postpartum women, it is suggested that family members, especially spouses and care providers, support mothers to strengthen their quality of life and prevent postpartum depression. Thus, PPD screening during routine postnatal care and improving the emotional and social health of women beyond their physical health are important to promote women's quality of life.

\section{Limitations of the study}

Due to the limited number of participants, it is not possible to generalize the data to the whole of community. Therefore, future studies with a larger sample size are suggested. The nutritional status, length of labour, use of oxytocin during labour, obstetrical complication, sleeping status and physical activity were not evaluated due to lack of accurate information. The recall biases of women could also reduce the accuracy of their responses.

\section{Conclusions}

In this research, about one in four women had postpartum depression, and the level of their quality of life was at a moderate level. Results showed postpartum depression could be predicted by mothers' quality of life. Thus, women need physiological, psychological and social support during pregnancy and after delivery from their spouse, family and health providers. On the other hand, early diagnosis of postpartum depression could decrease the consequences of mothers' depression, decrease the attachment between mother and child and improve family function. It is suggested that efforts be taken to increase the emotional heath of the mothers to promote their quality of life and decrease the risk of postpartum depression.

Source of funding: This work was funded by the Hamadan University of Medical Science.

Conflicts of interest: The authors declare no conflicts of interest.

\section{Referencess}

1. Brannon L, Feist J, Updegraff JA. Health psychology: an introduction to behavior and health. 8th ed. Boston: Cengage Learning; 2013 : 230-300.

2. Magesh P, Pooja S. Attitude on postpartum depression among women. International Journal for Research In Social Science and Humanities 2019; 5(3): 1-24. 
3. Fairclough DL. Design and analysis of quality of life studies in clinical trials. 2nd ed. Boca Raton, London, New York: CRC Press/Taylor \& Francis Group; 2010: 56-167.

4. Bahrami N, Bahrami S. The survey of quality of life in first-time women in postpartum period. IJNR 2012; 6(23): 58-64.

5. Shobeiri F, Manoucheri B, Parsa P, et al. Effects of counselling and sole reflexology on fatigue in pregnant women: a randomized clinical trial. J Clin Diagn Res 2017; 11(6): QC01-QC04, doi: 10.7860/JCDR/2017/22681.9972.

6. Sadat Z, Abedzadeh-Kalahroudi M, Atrian MK, et al. The impact of postpartum depression on quality of life in women after child's birth. Iran Red Crescent Med J 2014; 16(2): e14995, doi: 10.5812/ircmj.14995.

7. Meltzer-Brody S, Maegbaek M, Medland S, et al. Obstetrical, pregnancy and socio-economic predictors for new-onset severe postpartum psychiatric disorders in primiparous women. Psychol Med 2017; 47(8): 1427-1441.

8. Soltani F, Eskandari Z, Khodakarami B, et al. Factors contributing to fear of childbirth among pregnant women in Hamadan (Iran) in 2016. Electron Physician 2017; 9(7): 4725-4731.

9. Parsa P, Saiedzadeh N, Roshanaei G, et al. The effect of training on maternal-fetal attachment (MFA) in nulliparous women: a randomized clinical trial. Avecina J Nurs Midwifery Care 2016; 24(1): 24-30.

10. Bloch M, Rotenberg N, Koren D, et al. Risk factors for early postpartum depressive symptoms. Gen Hosp Psychiatry 2006; 28(1): 3-8.

11. Cunningham F, Leveno K, Bloom S, et al. Williams Obstetrics. 24th ed. New York: McGraw-Hill; 2014: 189-214.

12. Roch G, Borgès Da Silva R, de Montigny $F$, et al. Impacts of online and group perinatal education: a mixed methods study protocol for the optimization of perinatal health services. BMC Health Serv Res 2018; 18(1): 382, doi: 10.1186/s12913-018-3204-9.

13. Neri E, Agostini F, Salvatori P, et al. Mother-preterm infant interactions at 3 months of corrected age: influence of maternal depression, anxiety and neonatal birth weight. Front Psychol 2015; 6: 1234, doi: 10.3389/fpsyg.2015.01234.

14. Sadock BJ, Sadock VA. Kaplan and Sadock's synopsis of psychiatry: behavioral sciences/clinical psychiatry. Philadelphia: Lippincott Williams \& Wilkins; 2011.

15. Tel H, Pinar SE, Daglar G. Effects of home visits and planned education on mothers' postpartum depression and quality of life. $J$ Clin Exp Invest 2018; 9(3): 119-125.

16. American Psychiatric Association. Diagnostic and statistical manual of mental disorders (DSM-5 $\left.{ }^{\circledR}\right)$. Washington: APA; $2013: 101$.

17. Parsa P, Masoumi Z, Parsa N, et al. Parents' health beliefs influence breastfeeding patterns among Iranian women. Oman Med J 2015; 30(3): 187-192.

18. Ahmadi S, Kazemi F, Masoumi SZ, et al. Intervention based on BASNEF model increases exclusive breastfeeding in preterm infants in Iran: a randomized controlled trial. Int Breastfeed J 2016; 11(1): 30, doi: 10.1186/s13006-016-0089-2.

19. Nagata M, Nagai Y, Sobajima $H$, et al. Depression in the mother and maternal attachment - results from a follow-up study at 1 year postpartum. Psychopathology 2003; 36(3): 142-151.

20. Kokkinaki T. Maternal and paternal postpartum depression: effects on early infant-parent interactions. J Pregnancy Child Health 2016; 3(1): $1-5$.

21. Parsa N, Yaacob SN, Redzuan M, et al. Parental attachment, inter-parental conflict and late adolescent's self-efficacy. Asian Soc Sci 2014; 10(8): 123-131.

22. Parsa N, Redzuan Mr, Yaacob SN, et al. The mediating role of anxiety to perform social skills between parental attachment and adolescents' self-efficacy. Life Science Journal 2014; 11(10): 63-70.

23. Shobeiri F, Javad MT, Parsa P, et al. Effects of group training based on the health belief model on knowledge and behavior regarding the pap smear test in Iranian women: a quasi-experimental study. Asian Pac J Cancer Prev 2016; 17(6): 2871-2876.

24. Chalmers B, Mangiaterra V, Porter R. WHO principles of perinatal care: the essential antenatal, perinatal, and postpartum care course. Birth 2001; 28(3): 202-207.

25. Akbarzadeh M, Rad SK, Moattari M, et al. Investigation of breastfeeding training based on BASNEF model on the intensity of postpartum blues. East Mediterr Health J 2017; 23(12): 830-835, doi: 10.26719/2017.23.12.830.

26. Chang $\mathrm{SM}$, Chen $\mathrm{CH}$. Effects of an intervention with drinking chamomile tea on sleep quality and depression in sleep disturbed postnatal women: a randomized controlled trial. J Adv Nurs 2016; 72(2): 306-315.

27. Poyatos-León R, García-Hermoso A, Sanabria-Martínez G, et al. Effects of exercise-based interventions on postpartum depression: a meta-analysis of randomized controlled trials. Birth 2017; 44(3): 200-208.

28. Vaziri F, Shiravani M, Najib FS, et al. Effect of lavender oil aroma in the early hours of postpartum period on maternal pains, fatigue, and mood: a randomized clinical trial. Int J Prev Med 2017; 8: 29, doi: 10.4103/ijpvm.IJPVM_137_16.

29. Rezaie-Keikhaie K, Hastings-Tolsma M, Bouya S, et al. Effect of aromatherapy on post-partum complications: a systematic review. Complement Ther Clin Pract 2019; 35: 290-295.

30. Buttner MM, Brock RL, O'Hara MW, et al. Efficacy of yoga for depressed postpartum women: a randomized controlled trial. Complement Ther Clin Pract 2015; 21(2): 94-100.

31. Thitipitchayanant K, Somrongthong R, Kumar R, et al. Effectiveness of self-empowerment-affirmation-relaxation (Self-EAR) program for postpartum blues mothers: a randomize controlled trial. Pak J Med Sci 2018; 34(6): 1488-1493.

32. Top ED, Karaçam Z. Effectiveness of structured education in reduction of postpartum depression scores: a quasi-experimental study. Arch Psychiatr Nurs 2016; 30(3): 356-362.

33. Fonseca A, Gorayeb R, Canavarro MC. Women's help-seeking behaviours for depressive symptoms during the perinatal period: sociodemographic and clinical correlates and perceived barriers to seeking professional help. Midwifery 2015; 31(12): 1177-1185.

34. Mgonja S, Schoening A. Postpartum depression screening at well-child appointments: a quality improvement project. $J$ Pediatr Health Care 2017; 31(2): 178-183.

35. Wilkinson A, Anderson S, Wheeler SB. Screening for and treating postpartum depression and psychosis: a cost-effectiveness analysis. Matern Child Health J 2017; 21(4): 903-914.

36. Setodeh $\mathrm{S}$, Sharif $\mathrm{F}$, Akbarzadeh $\mathrm{M}$. The impact of paternal attachment training skills on the extent of maternal neonatal attachment in primiparous women: a clinical trial. Fam Med Prim Care Rev 2018; 20(1): 47-54.

37. Mogos MF, August EM, Salinas-Miranda AA, et al. A systematic review of quality of life measures in pregnant and postpartum mothers. Appl Res Qual Life 2013; 8(2): 219-250.

38. Gale S, Harlow B. Postpartum mood disorders: a review of clinical and epidemiological factors. J Psychosom Obstet Gynecol 2003; 24(4): 257-266.

39. Montazeri A, Torkan B, Omidvari S. The Edinburgh Postnatal Depression Scale (EPDS): translation and validation study of the Iranian version. BMC Psychiatry 2007; 7(1): 1, doi: 10.1186/1471-244X-7-11.

40. Moraes IGdS, Pinheiro RT, Silva RAd, et al. Prevalence of postpartum depression and associated factors. Revista de Saúde Pública 2006; 40(1): 65-70.

41. Tannous L, Gigante LP, Fuchs SC, et al. Postnatal depression in Southern Brazil: prevalence and its demographic and socioeconomic determinants. BMC Psychiatry 2008; 8(1): 1, doi: 10.1186/1471-244X-8-1. 
42. Lashkaripour K, Bakhshani NM, Hokmabadi S, et al. Postpartum depression and related factors: a 4.5 months study. The Quarterly Journal of Fundamentals of Mental Health 2012; 13(4): 402-412.

43. Lara-Cinisomo S, Girdler SS, Grewen K, et al. A biopsychosocial conceptual framework of postpartum depression risk in immigrant and US-born Latina mothers in the United States. Women's Health Issues 2016; 26(3): 336-343.

44. Alhamdan N, Ajaj A, Alali F, et al. Postpartum depression and health related quality of life: a necessary assessment. Int J Fam Commun Med 2017; 1(1): 11-17.

45. Kohler S, Annerstedt KS, Diwan V, et al. Postpartum quality of life in Indian women after vaginal birth and cesarean section: a pilot study using the EQ-5D-5L descriptive system. BMC Pregnancy Childbirth 2018; 18(1): 427, doi: 10.1186/s12884-018-2038-0.

46. Waldrop J, Ledford A, Perry LC, et al. Developing a postpartum depression screening and referral procedure in pediatric primary care. J Pediatr Health Care 2018; 32(3): e67-e73, doi: 10.1016/j.pedhc.2017.11.002.

47. Closa-Monasterolo R, Gispert-Llaurado M, Canals J, et al. The effect of postpartum depression and current mental health problems of the mother on child behaviour at eight years. Matern Child Health J 2017; 21(7): 1563-1572.

48. Gharacheh M, Ranjbar F, Azadi S. Women's quality of life and postpartum depression. Iran Journal of Nursing 2018; 30(110): 68-77.

49. Da Costa D, Dritsa M, Rippen N, et al. Health-related quality of life in postpartum depressed women. Arch Womens Ment Health 2006; 9(2): 95-102.

50. Zubaran C, Foresti K. Investigating quality of life and depressive symptoms in the postpartum period. Women Birth 2011; 24(1): 10-16.

51. Feki R, Feki I, Trigui D, et al. Impact of postpartum depression on quality of life. European Psychiatry 2017; 41(Suppl.): S901-S902.

Tables: 3

Figures: 0

References: 51

Received: 6.03 .2019

Reviewed: 13.03 .2019

Accepted: 5.05.2019

Address for correspondence:

Parisa Parsa, PhD, Assoc. Prof.

Chronic Diseases Home Care Research Center

Hamadan University of Medical Sciences

Hamadan

Iran

Tel.: +98 9183129378

E-mail: pparsa2003@yahoo.com 